\title{
Age determination and shell growth of Chamelea gallina (Bivalvia: Veneridae) in the western Mediterranean
}

\author{
M. Ramón ${ }^{1}$, C. A. Richardson ${ }^{2}$ \\ 'Instituto de Ciencias del Mar (C.S.I.C.), Paseo Nacional s/n, E-08039 Barcelona, Spain \\ ${ }^{2}$ School of Ocean Sciences, University of Wales, Bangor, Marine Science Laboratories, Menai Bridge, Anglesey LL59 5EY, \\ United Kingdom
}

\begin{abstract}
The pattern of microgrowth bands in shell sections of the Mediterranean clam Chamelea gallina shows a seasonal variation in width. Widely spaced growth bands are formed in winter and late spring between January and June, whilst narrow growth increments are deposited in summer and early autumn between August and October, following the maximum summer seawater temperature. The warm summer seawater temperature of $33^{\circ} \mathrm{C}$ in the western Mediterranean may be responsible for the suppression of shell growth, as evidenced both by the narrowing of the growth increments and by the later appearance of clefts in shell sections. There is no correlation between spawning and the formation of clefts in the shell of $C$. gallina. The annual pattern of narrow and wide growth increments has been used to estimate the age of $C$. gallina and to construct growth curves for this species from the eastern coast of Spain. Growth curves for the clams, determined from the internal microgrowth bands and from the spacing between the clefts in shell sections, differed from the curve calculated using surface growth rings
\end{abstract}

\section{INTRODUCTION}

The bivalve Chamelea gallina (Linneo, 1758) is commonly found in the Mediterranean Sea at depths between 3 and $7 \mathrm{~m}$ where it inhabits well-sorted fine sand biocoenosis (Picard 1965). C. gallina is of considerable commercial importance, as it forms an important fishery in the inshore waters of Italy, Spain, Turkey and Morocco. However, the population dynamics of the species in the Mediterranean Sea are poorly known.

Studies of the population dynamics of bivalves require a knowledge of the growth and age of individual organisms within the population. Age and growth rate can be estimated using a variety of methods, including an analysis of size-frequency distributions, surface shell rings and internal shell banding patterns.

The Chamelea gallina population from the eastern coast of Spain shows 2 interesting features. Firstly, it is an exploited population, most large individuals having been removed by local fishing activity, and secondly, the interpretation of the external growth rings on the shell surface is not clear. The periodicity of the rings is unknown, and they could easily be confused with disturbance rings caused by fishing activity. As part of a wider study of the ecology of C. gallina in the Mediterranean, it was essential to the understanding of the population structure to establish a method for determining the age of individuals within the population.

Recently methods have been developed in which acetate peel replicas of polished and etched radial shell sections are examined in a light microscope for the presence of microscopic tidal, daily or annual growth lines (Richardson 1987, 1988, 1989, Evans 1988, Trutschler \& Samtleben 1988, Anwar et al. 1990 , Bourget \& Brock 1990). Counts of the number of growth lines and measuring the separation of the bands and lines within the shell allow an estimate of the age and growth rate to be made.

Previous studies on the age and growth rate of Chamelea gallina in the Mediterranean have 
employed length-frequency distributions (Froglia 1975, Bodoy 1983), whilst others have examined surface shell rings (Vives \& Suau 1962, Poggiani et al. 1973, Marano et al. 1982, Vizuete et al. 1990). Internal microgrowth lines have not hither to been identified in this species.

In this paper we examine the age structure and estimate the growth rate of an exploited population of Chamelea gallina from the eastern coast of Spain using size-frequency distributions, surface growth rings and internal shell microgrowth banding patterns

\section{MATERIALS AND METHODS}

Samples of Chamelea gallina were collected from a water depth of $5 \mathrm{~m}$ at approximately monthly intervals between June 1989 and June 1990 from Cullera, on the eastern coast of Spain. Only a few of the C. gallina collected with a commercial dredge were smaller than $15 \mathrm{~mm}$ and larger than $30 \mathrm{~mm}$ shell length. In order to study the size distribution of the smaller size classes, a dredge with a small mesh size $(4 \times 4 \mathrm{~mm})$ was also used between August 1989 and May 1990 to collect young clams from the population. The anterior-posterior length of each of the clams was measured to the nearest $0.1 \mathrm{~mm}$ using an automatic sliding vernier caliper and a size-frequency distribution constructed for each of 8 monthly samples. During June and July 1989 too few C. gallina were collected to enable sizefrequency distributions to be constructed. By plotting the change of position of each mode over time, a growth curve was derived. Sub-samples of 10 shells with a size range of 13 to $34 \mathrm{~mm}$ were taken each month. The right valve of each of the shells was embedded in resin (Fontanals, S.A., Spain) and then sectioned from the umbo to the ventral margin along the axis of maximum growth. Acetate peel replicas of the sectioned, ground, polished and etched surfaces were then prepared using the technique described by Richardson et al. (1979), but with the modification of etching for 18 to $20 \mathrm{~min}$ in $0.01 \mathrm{M} \mathrm{HCl}$. Acetate peels were examined under a low power objective $(\times 10)$ in a transmitted light-microscope. A cursory examination of the peels showed that the separation of the microgrowth bands and position of clefts varied along the length of the shell. In order to quantify whether there was a seasonal variation in band separation and cleft formation, the number of clefts in the most recently deposited $2 \mathrm{~mm}$ of shell and the number of bands in the last $0.5 \mathrm{~mm}$ of shell at the ventral margin were counted. The positions where the bands were observed to narrow were marked directly on the peel using a black marker pen, counted and compared where appropriate with the position and counts of the surface growth rings. Growth curves were constructed using data from both internal bands and surface growth rings. A comparison among the growth curves obtained from the size-frequency distributions, acetate peels and shell rings was made.

\section{RESULTS}

\section{Analysis of size-frequency distributions}

Fig. 1 follows a cohort of Chamelea gallina which had recruited into the population during 1989. Despite markedly variable individual growth rates, resulting in an increased dispersion about the mean, the cohort remained relatively discrete during the year of study, although in the April and May samples there was a very pronounced dispersion about the mean. The increase in mean length of the 1989 year class (Fig. 1) shows that the mean period of sheil growth took place between January and May 1990.

\section{Shell microgrowth patterns}

The shell of Chamelea gallina consists principally of 2 aragonitic layers: an outer shell layer subdivided into 2 sublayers, the outer prismatic layer and middle crossed lameller layer; and an inner homogeneous layer (Alemany 1986-1987). Fig. 2 illustrates a diagrammatic radial section through the shell showing the different layers.

Figs. 3 to 7 illustrate the appearance of acetate peels from sections through the shell of Chamelea gallina. Growth bands delineated by dark lines (Fig. 3) are deposited in the shell approximately parallel to the truncated region at the growing point of the shell. The distance separating 2 bands is termed the growth increment. In the prismatic layer the width of the growth increments and their clarity vary along the length of the shell; in some regions the bands are widely spaced (Fig. 3) whilst in other regions they are narrow (Fig. 5). Some of the bands are strong in definition (e.g. Gb in Fig. 3) while others are weakly defined (arrows in Fig. 5). Occasionally 2 bands are deposited very close together, giving the appearance of a double band (large arrow in Fig. 3). Growth patterns were also observed in the homogeneous layer and in the umbo region (arrows in Figs, 6 \& 7). Occasionally, block-like structural components of the shell were observed between the outer prismatic and middle crossed lameller layer, presumably interlocking these 2 layers together (arrow in Fig. 4).

In this study it was not possible to conduct field growth experiments with which to validate the period- 
icity of the microgrowth patterns. Instead an aiternative method was employed to investigate whether there was any seasonal pattern to the formation of the growth bands. Counts of the number of bands in the most recently deposited $0.5 \mathrm{~mm}$ of shell in the ventral shell margin were made. Fig. 8 shows the seasonal variation in the mean number of bands per $0.5 \mathrm{~mm}$ deposited in the shells of Chamelea gallina collected during 1989 and 1990. When there is a high number of bands per unit area then this indicates a slow rate of shell deposition, and conversely a small number of bands per unit area indicates a high rate of growth. Between August and October narrow bands were laid down, whereas widely spaced bands were formed between January and June. The pattern as a whole follows the seasonal variation in water temperature, but there is far from exact correspondence. The maximum number of bands per $0.5 \mathrm{~mm}$ does not coincide with the maximum water temperature, the former occurring 2 to 3 mo after the temperature maximum. During periods of slow growth the estimate of band numbers could cover several months' shell formation and it is likely, therefore, that there will not be an exact correlation between the 2 variables. Nevertheless, the decrease in the number of bands per $0.5 \mathrm{~mm}$ (i.e. an increase in the width of the increments) closely follows the decrease in water temperature during 1989 and early 1990. During April the water temperature begins to increase with the concomitant increase in the frequency of the bands (i.e. a narrowing of the width of the increments). This seasonal variation in the pattern of narrow and wide bands was used to ascertain positions of minimum and maximum growth along the shell. Three positions of minimum growth have been marked on the shell section shown in Fig. 9

In all the shells examined, clefts were present on the surface of the outer shell layer which appeared to coincide with a narrowing of the microgrowth bands (Figs. 10 to 15). The figures illustrate the positions of the first (Fig. 10), second (Figs. 11 \& 12) and third (Figs. 13\& 14) annual growth lines. In order to confirm whether clefts were associated with the narrowing of the bands during August and October, the incidence of clefts at the shell margin was also recorded from the acetate peels. Fig. 18A illustrates that there was a sudden increase in the number of clefts during October at a time when growth was slowest. Clefts were also observed in samples collected in January and February. This is not surprising since the number of clefts recorded relates to counts made in the most recently deposited $2 \mathrm{~mm}$ of shell at the ventral shell margin, and clefts will therefore occur near the shell margin in samples collected in January and February. The data in Fig. 18B clearly show that the clefts begin to form in the shells during October. Here the distance between the cleft and shell margin has been plotted to illustrate that the clefts appear seasonally in October when the bands are at their narrowest. The position of the clefts along the shell has, along with the associated narrowing of the bands, been used to estimate the age of the shells in the population. Fig. 15 shows a section through a clam shell collected during December 1989. A cleft associated with wide growth increments can be seen close to the shell margin. However, shells col-
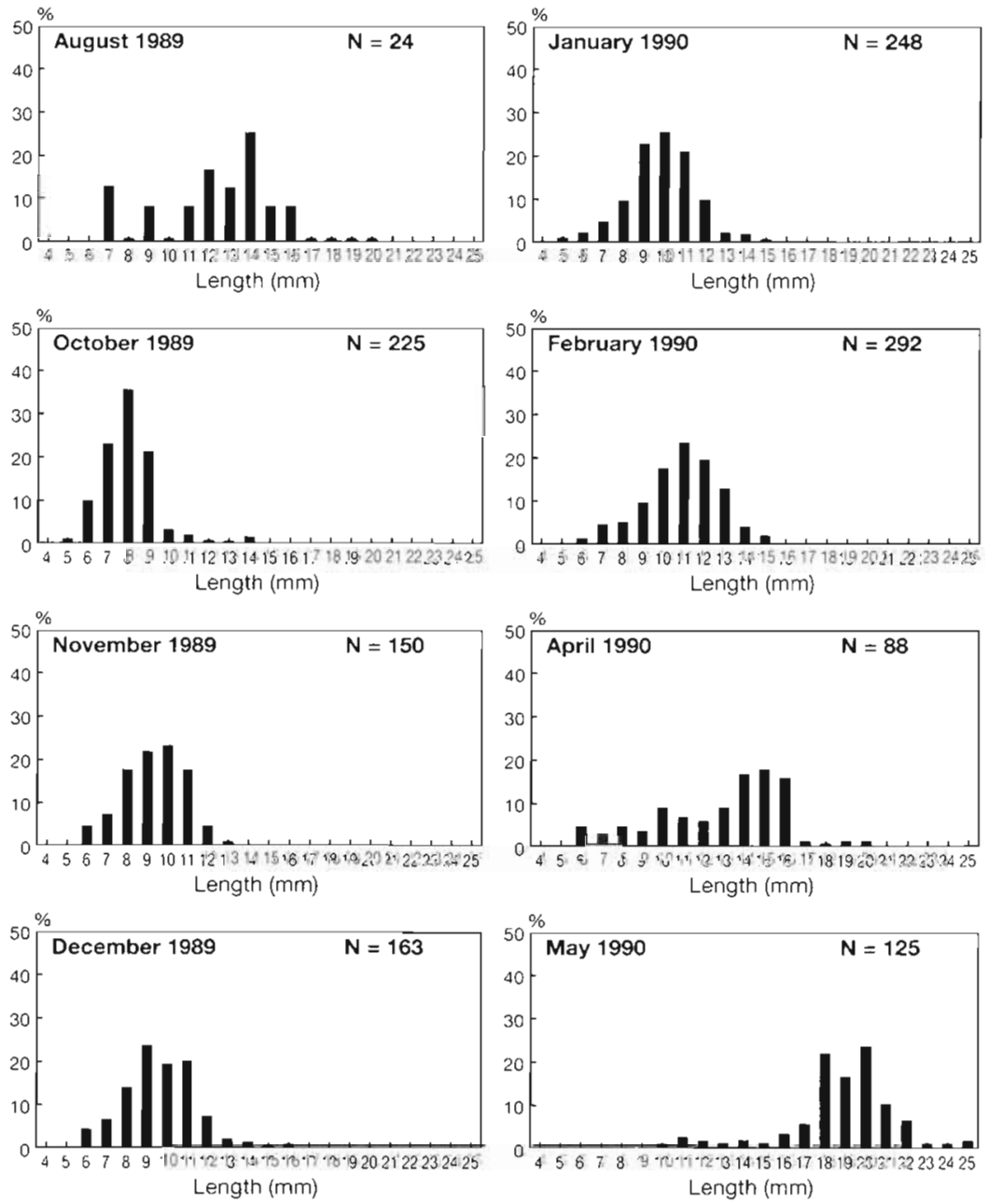

Fig. 1. Chamelea gallina. Monthly size-frequency distributions for clams from Cullera on the eastern coast of Spain 

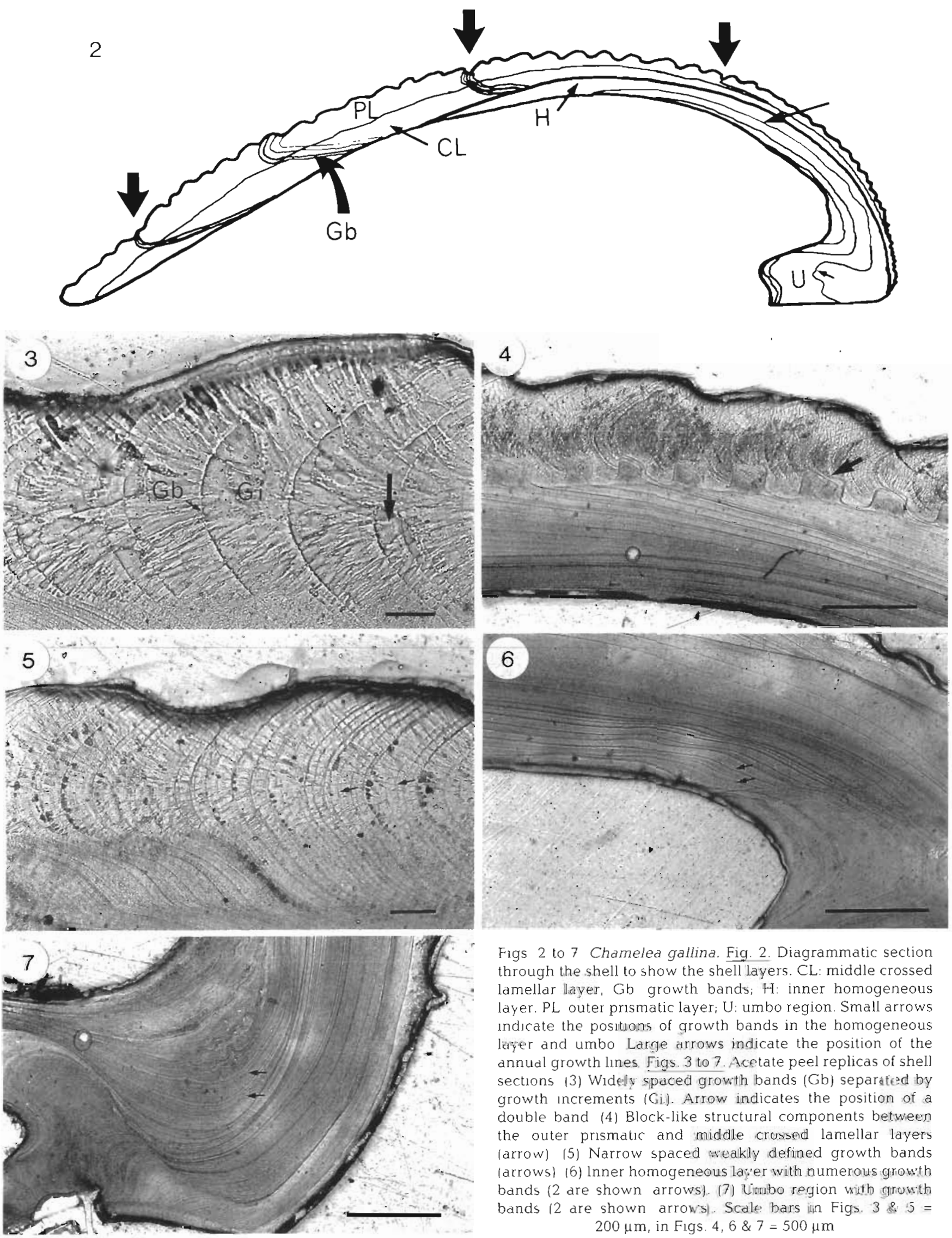

Figs 2 to 7 Chamelea gallina. Fig. 2. Diagrammatic section through the shell to show the shell layers. CL: middle crossed lamellar laver, $\mathrm{Gb}$ growth bands; $\mathrm{H}$ : inner homogeneous layer. PL outer prsmatic layer; U: umbo region. Small arrows indicate the positions of growth bands in the homogeneous layer and umbo Large arrows indicate the position of the annual growth lines. Figs. 3 to 7 . Acetate peel replicas of shell sections (3) Widely spaced growth bands (Gb) separated by growth increments (Gi). Arrow indicates the position of a double band (4) Block-like structural components between the outer prismatic and middle crossed lamellar layers (arrow) (5) Narrow spaced weakly defined growth bands (arrows) (6) lnner homogeneous layer with numerous growth bands ( 2 are shown arrows). (7) Umbo region with growth bands $(2$ are shown arrows). Scale bars in Figs, $3 \& 5=$ $200 \mu \mathrm{m}$, in Figs. $4,6 \& 7=500 \mu \mathrm{m}$ 
lected previously in August (Fig. 16) did not show evidence of clefts at the margin, nor did those sampled in April (Fig. 17).

The results of the determination of Chamelea gallina age using size-frequency analysis, surface growth rings, internal bands and clefts are shown in Fig $19 \mathrm{~A}$ to $\mathrm{D}$. The figure shows there are markedly variable individual growth rates resulting in a large dispersion about the mean.

\section{DISCUSSION}

Polished and etched shell sections of Chamelea gallina contain microgrowth bands which vary in width along the entire length of the shell. From monthly collections of shells it has been shown that narrow bands (Fig. 16) form during the warm summer months, between August and October when the water temperature varies between 33 and $27^{\circ} \mathrm{C}$, whilst widely spaced bands (Fig. 17) are deposited between January and June when seawater temperatures occur in the range 13 to $20^{\circ} \mathrm{C}$. In temperate waters, narrow growth bands in the shells of cockles Cerastoderma edule (Richardson et al. 1980) are associated with slow shell growth, but are formed instead during the colder winter months when water temperatures are at a minimum. Whether the reduced shell growth rates in Chamelea gallina are due to suppression by the high summer water temperatures alone is unclear A combination of both elevated water temperatures and possibly reduced phytoplankton production and summer oxygen depletion between August and October may be the factors responsible for the slower shell growth rates, but this requires further study.

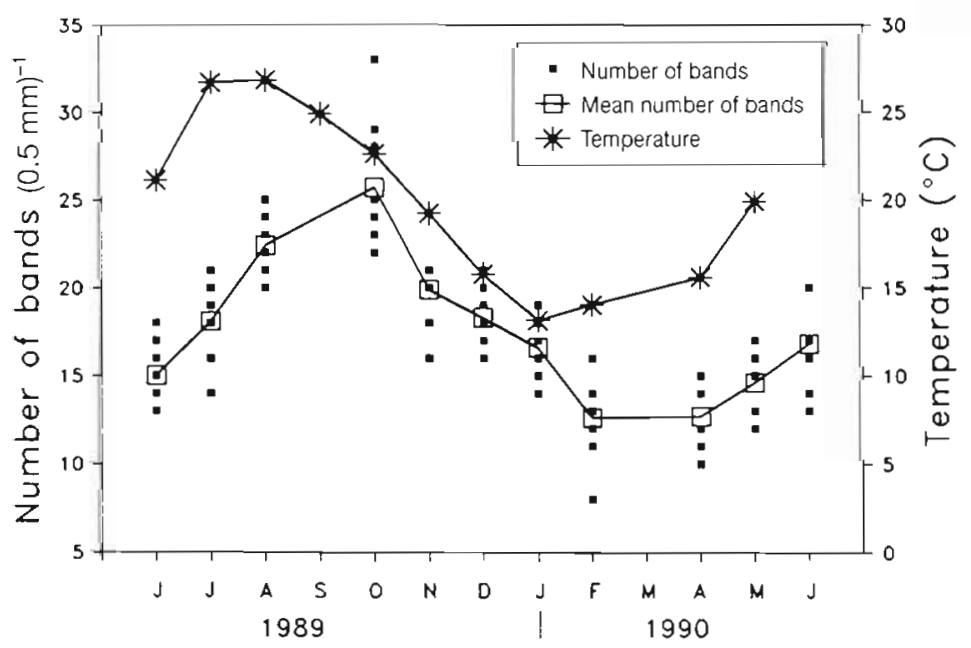

Fig. 8. Chamelea gallina. A comparison of the seasonal variation in number of bands per $0.5 \mathrm{~mm}$ with the seawater temperature

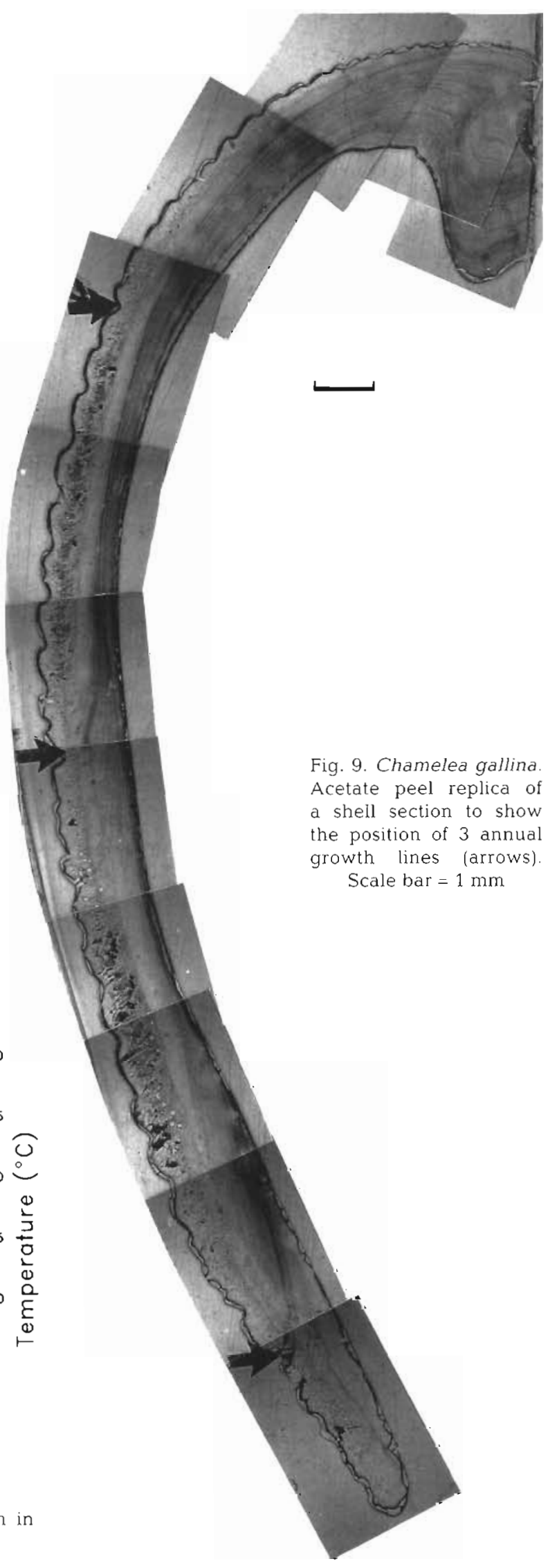



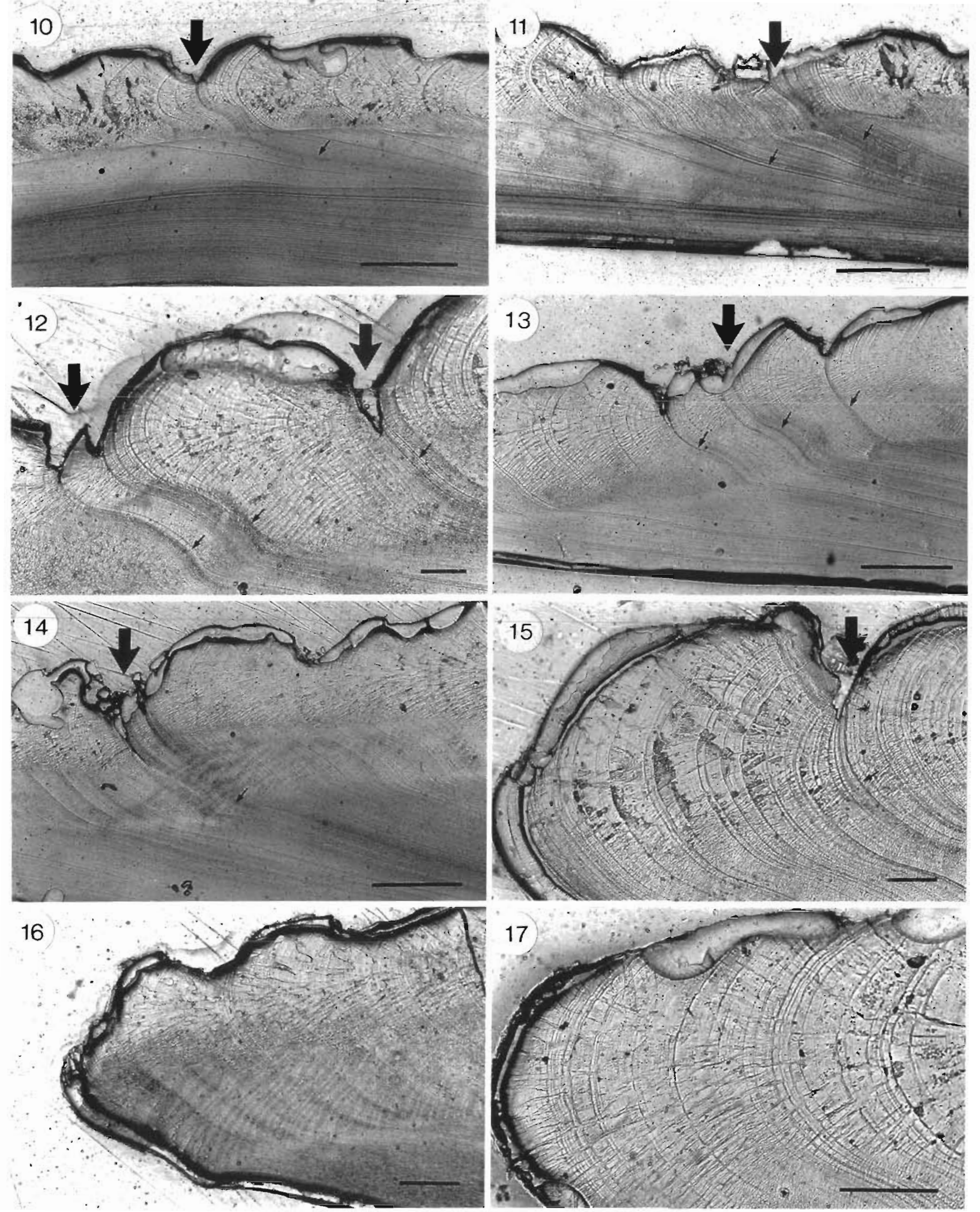
The possibility exists that the formation of clefts in Chamelea gallina during October may be the result of spawning events, since similar marks in other bivalves such as clams Mercenaria mercenaria are thought to be the result of spawning (Kennish 1980, Lutz \& Rhoads 1980). Ramón (1990), however, has shown that spawing of C. gallina occurs during the early summer in June and July in this Mediterranean region, so the spawning event itself is unlikely to interrupt shell growth. The processes leading to spawning may involve an increase in energy requirements and this, followed by warm summer seawater temperatures and paucity of food, may be sufficient to interfere with normal shell growth and result in a subsequent narrowing of bands and the formation of a cleft. Whatever the reasons are for the seasonal variations in shell growth, the annual pattern of narrow and wide bands has been used successfully in this study to estimate the age of C. gallina and to construct growth curves for this species. Independent evidence to support the seasonal variation in shell growth is provided from an analysis of the monthly sizefrequency distributions (Fig. 1). The first sample collected in August 1989 shows the appearance of a newly recruited cohort. Little shell growth takes place between October and December 1989, with the newly recruited clams 'overwintering' at a size of about 8 to $9 \mathrm{~mm}$. The main period of growth takes place between January and May 1990 prior to the spawning period in June, after which the new recruits would be anticipated to appear in the population.

The Von Bertalanffy growth curves shown in Fig. 19 clearly show the importance of determining growth rates from the microgrowth patterns in shell sections. Of the shells examined in this study some $20 \%$ had no distinct surface rings. The curve plotted from data obtained from the surface rings shows that clams less than 1 yr old would have a size range between 13 and $27 \mathrm{~mm}$ (Fig. 19A), a different size from that obtained from an analysis of the size-frequency distributions (Fig. 19D). The growth curves obtained from the growth bands and clefts are similar in appearance but different from the growth ring data. During the first year of growth there is a clear difference between the surface ring method and the internal patterns. By the second year the 3 curves have merged. Yet it is during the first $2 \mathrm{yr}$ of life that important information on growth rates is required for population studies.
The periodicity of the microgrowth patterns observed in the shells of Chamelea gallina could not be established in this study. In the Mediterranean there is only a small tidal rise and fall which might produce the observed semidiurnal growth patterns seen in the shells of temperate intertidal species. Studies on the periodicity of microgrowth patterns in the shells of clams Tapes philippinarum (Richardson 1988) and mussels Mytilus edulis (Richardson 1989) grown continuously immersed in natural field and laboratory conditions have shown that the bands are weaker in definition than in intertidal conspecifics. The production of the bands is related to an endogenous rhythm of shell formation and not to exogenous factors such as diurnal fluctuations and tidal or
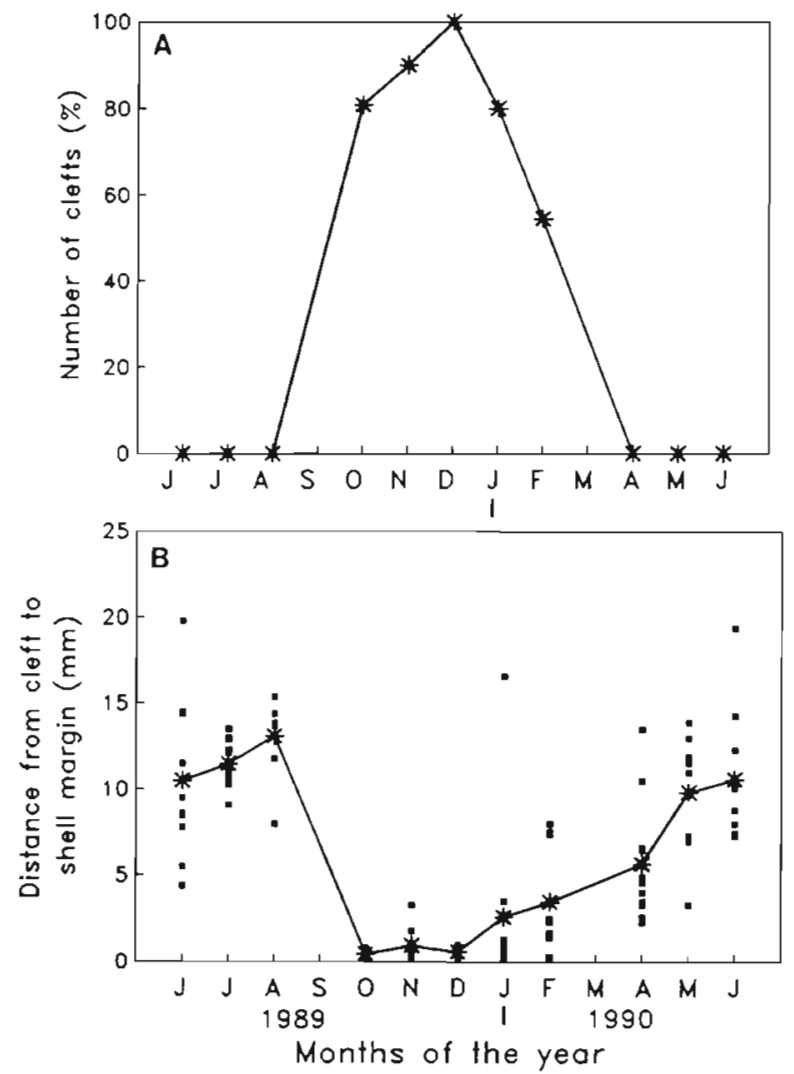

Fig. 18. Chamelea gallina. (A) Seasonal variation in the number of clefts in monthly collections of shells. (B) Seasonal variation in the time of formation of clefts in the shell. Clefts first appear at the shell margin in shells collected during October

Figs. 10 to 17. Chamelea gallina. Acetate peel replicas of shell sections to show clefts and annual growth lines (arrows). Fig. 10. First annual growth line. Figs. 11 \& 12. Second annual growth lines. Figs. 13 \& 14. Third annual growth lines. Fig. 15. Cleft (arrow) and wide growth increments at the shell margin in a shell collected during December 1989. Fig. 16. Narrowly spaced growth bands deposited in a shell collected in August 1989. Fig. 17. Widely spaced growth bands depasited in a shell collected in April 1990. Scale bars in Figs. $10,11,13 \& 14=500 \mu \mathrm{m}$; in Figs. $12,15,16 \& 17=200 \mu \mathrm{m}$ 

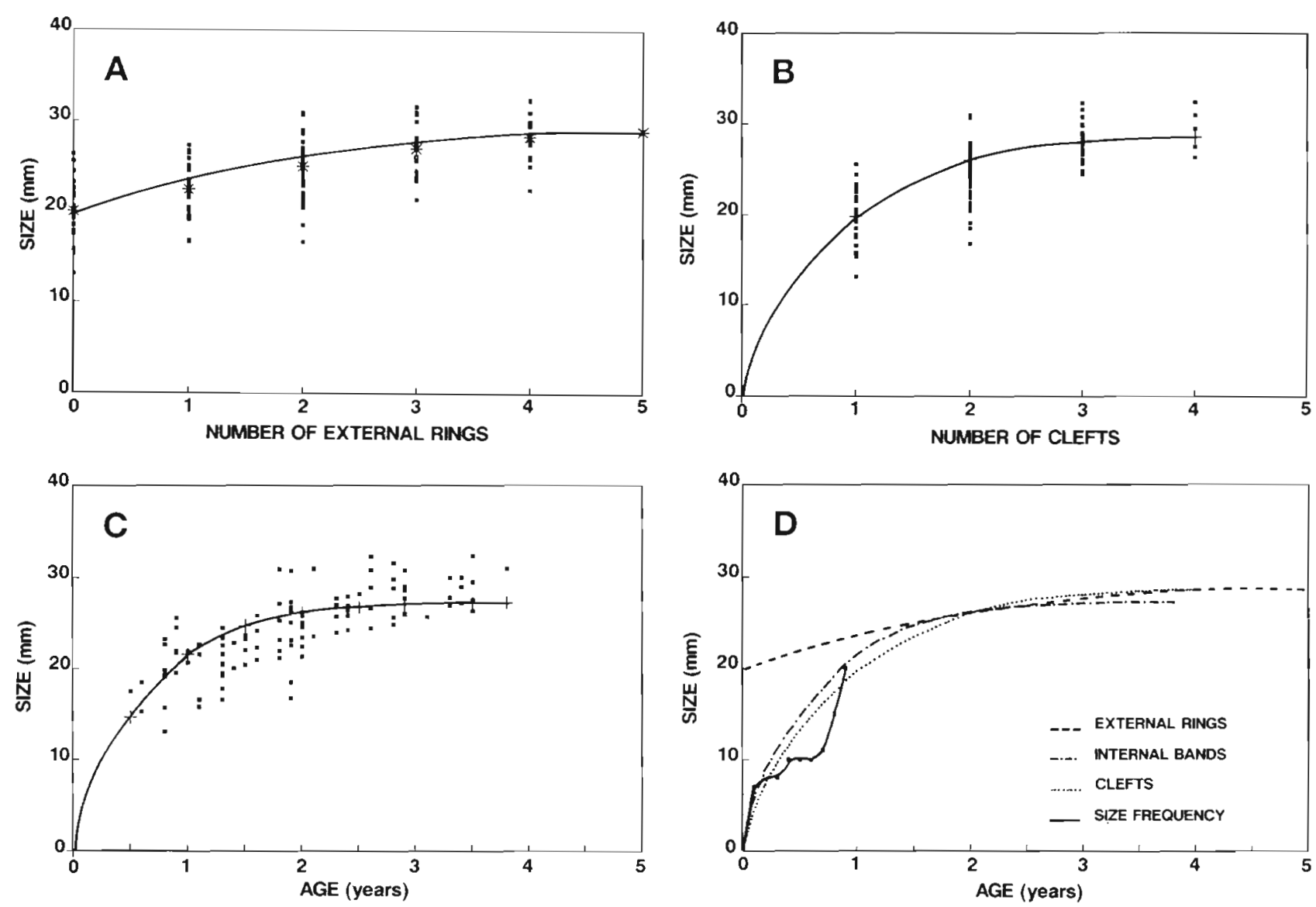

Fig. 19. Chamelea gallina. Growth curves determined from (A) external growth rings, (B) clefts in acetate peels of shell sections, and (C) growth bands in acetate peel replicas of shell sections. Curves fitted by the Von Bertalanffy growth equation. (D) Comparison of the growth curves determined using surface growth rings, clefts and growth bands with data obtained from the size-frequency distributions shown in Fig. 1

current flow. The bands in C. gallina may also be an expression of an endogenous rhythm. Certainly there is increasing evidence that the production of microgrowth bands in subtidal bivalves may be under endogenous control (Richardson 1991) rather than daily or tidal control (Lutz \& Rhoads 1980). In the Mediterranean, where there are no tides, the formation of microgrowth bands is likely to be controlled by an innate rhythm and therefore the bands cannot be used to measure tidal or daily growth rates, a method previously used to assess shell growth rates in intertidal bivalves (Richardson et al. 1980).

Acknowledgements. We thank Dr P. Abelló for all his help and encouragement during the development of this study. We also thank Dr J. Lleonart, Director of the 'Localización y estudio de los bancos de bivalvos del hitoral valenciano' programme, for his valuable support.

\section{LITERATURE CITED}

Alemany, J. A. (1986-1987). Comparison morphologique de la structure de la coquille et de l'enroulement en spirale chez Chamelea gallina (Mörch, 1853) et chez Venus verrucosa, L. 1758, (Mollusca: Bivalvia). Arch. Anat. micro. Morphol. expér. 75: 61-74

Anwar, N. A., Richardson, C. A., Seed, R. (1990). Age determination, growth rate and population structure of the horse mussel Modiolus modiolus. J. mar. biol. Ass. U.K. 70: $441-457$

Bodoy, A. (1983). Croissance et variations saisonnières de la composition biochimique de Venus gallina dans le Golfe de Marseille (Méditerranée occidentale). Tethys 11: 57-66

Bourget, E., Brock, V. (1990). Short-term shell growth in bivalves: individual, regional, and age-related variations in the rhythm of deposition of Cerastoderma (= Cardium) edule. Mar. Biol. 106: 103-108

Evans, J. W. (1988). Cockle diaries: the interpretation of tidal growth lines. Endeavour (New Ser.) 12: 8-15

Froglia, C. (1975). Osservazioni sull'accrescimento di Chamelea gallina (L.) ed Ensis minor (Chenu) nel medio Adriatico. Quad. Lab. Tecnol. Pesca. 2: 37-48 
Kennish, M. J. (1980). Shell microgrowth analysis: Mercenaria mercenaria as a type example for research in population dynamics. In: Rhoads, D. C., Lutz, R. A. (eds.) Skeletal growth of aquatic organisms. Plenum Press, New York, p. 255-292

Lutz, R. A., Rhoads, D. C. (1980). Growth patterns within the molluscan shell: an overview. In: Rhoads, D. C., Lutz, R. A. (eds.) Skeletal growth of aquatic organisms. Plenum Press, New York, p. 203-248

Marano, G., Casavola, N., Saracino, C., Rizzi, E. (1982). Riproduzione e crescita di Chamelea gallina (L.) e Venus verrucosa (L.) (Bivalvia: Veneridae) nel basso Adriatico. Mem. Biol. Mar. Oceanogr. 12: 93-110

Picard, J. (1965). Recherches qualitatives sur les biocoenoses marines des substrats meubles dragables de la région Marseillaise. Rec. Trav. Sta. mar. Endoume 52: 1-160

Poggiani, L., Piccinetti, C., Picinetti Manfrin, G. (1973). Osservazioni sulla biologia dei molluschi bivalvi Venus gallina L. e Tapes aureus Gmelin nell'Alto Adriatico. Note Lab. Biol. Mar. Pesca-Fano 4: 189-212

Ramón, M. (1990). Estudio del ciclo ovarico de Chamelea gallina (Linneo, 1758) del golfo de Valencia. Iberus 9: $175-179$

Richardson, C. A. (1987). Microgrowth bands in the shell of the Malaysian cockle Anadara granosa and their use in age determination. J. exp. mar. Biol. Ecol. 111: 77-98

Richardson, C. A. (1988). Tidally produced bands in the shell

This article was submitted to the editor of Spisula subtruncata (Da Costa). J. Mollusc. Stud. 54: 71-82

Richardson, C. A. (1989), An analysis of the growth bands in the shell of the common mussel Mytilus edulis. J. mar. biol. Ass. U.K. 69: 477-491

Richardson, C. A. (1991). Tidal rhythms in the shell secretion of living bivalves. In: Brosche, P., Sundermann, J. (eds.) Earth's rotation from eons to days. Springer-Verlag, Berlin, p. 215-226

Richardson, C. A., Crisp, D. J., Runham, N. W. (1979). Tidally deposited growth bands in the shell of the common cockle Cerastoderma edule (L.). Malacologia 18: 277-290

Richardson, C. A., Crisp, D. J., Runham, N. W., Gruffydd, L. L. D. (1980). The use of tidal growth bands in the shell of Cerastoderma edule to measure seasonal growth rates under cool temperate and subarctic conditions. J. mar. biol. Ass. U.K. 60: 977-989

Trutschler, K., Samtleben, C. (1988). Shell growth of Astarte elliptica (Bivalvia) from Kiel Bay (western Baltic Sea). Mar Ecol. Prog. Ser. 42: 155-162

Vives, F., Suau, P. (1962). Sobre la chirla (Venus gallina L.) de la desembocadura del rio Ebro. Invest. pesq. 21: 145-163

Vizuete, F., Martinez, P., Mas, J., Faraco, F. (1990). Estudio del banco natural de chirla (Chamelea gallina L., 1758) de San Ginés (T. M. Cartagena). In: Estudios sobre pesquerias y cultivos marinos en la región de Murcia. Comunidad Autónoma de la región de Murcia, p. 49-69

Manuscript first received: March 31, 1992

Revised version accepted: October 14, 1992 